\title{
GM-CSF Transgene Expression in the Airway Allows Aerosolized Ovalbumin to Induce Allergic Sensitization in Mice
}

\author{
Martin R. Stämpfli, Ryan E. Wiley, G. Scott Neigh, Beata U. Gajewska, Xue-Feng Lei, Denis P. Snider, Zhou Xing, \\ and Manel Jordana \\ Department of Pathology and Molecular Medicine, Immunology and Infection Programme, and Centre for Gene Therapeutics, McMaster \\ University, Hamilton, Ontario, Canada L8N $3 Z 5$
}

\begin{abstract}
The purpose of this study was to explore whether repeated exposure to aerosolized ovalbumin (OVA) in the context of local expression of GM-CSF can initiate a Th2-driven, eosinophilic inflammation in the airways. On day -1 , Balb/c mice were infected intranasally with an adenovirus construct expressing GM-CSF (Ad/GM-CSF). From day 0 to day 9 mice were exposed daily to an OVA aerosol. Mice exposed to OVA alone did not show any evidence of airway inflammation. Mice receiving both Ad/GM-CSF and aerosolized OVA exhibited marked airway inflammation characterized by eosinophilia and goblet cell hyperplasia. Migration of eosinophils into the airway was preceded by a rise in IL-5 and IL-4. Both IL-5 and class II MHC were critically required to generate airway eosinophilia. After resolution, airway eosinophilia was reconstituted after a single OVA exposure. Flow cytometric analysis of dispersed lung cells revealed an increase in macrophages and dendritic cells expressing B7.1 and B7.2, and expansion of activated (CD69expressing) CD4 and CD8 $\mathrm{T}$ cells in mice exposed to OVA and Ad/GM-CSF. Our data indicate that expression of GMCSF in the airway compartment increases local antigen presentation capacity, and concomitantly facilitates the development of an antigen-specific, eosinophilic inflammatory response to an otherwise innocuous antigen. (J. Clin. Invest. 1998. 102:1704-1714.) Key words: airway inflammation • GM-CSF • ovalbumin • eosinophils • mice
\end{abstract}

\section{Introduction}

The airways, like all mucosal surfaces, represent a site of initial exposure to environmental agents (1). It is at the mucosal surface that antigens are captured by antigen-presenting cells (APCs). ${ }^{1}$ They are subsequently processed and presented to

\footnotetext{
Address correspondence to Manel Jordana, M.D., Ph.D., Health Sciences Centre, Room 4H21, Department of Pathology, McMaster University, 1200 Main Street West, Hamilton, Ontario, Canada L8N 3Z5. Phone: 905-525-9140, ext. 22473; FAX: 905-522-6750; E-mail: jordanam@fhs.csu.mcmaster.ca

Received for publication 1 June 1998 and accepted in revised form 3 September 1998.
}

1. Abbreviations used in this paper: Ad, adenoviral; APC, antigenpresenting cell; BAL, bronchoalveolar lavage; i.n., intranasally; $\mathrm{KO}$, knockout; OVA, ovalbumin.

J. Clin. Invest.

(C) The American Society for Clinical Investigation, Inc. 0021-9738/98/11/1704/11 \$2.00

Volume 102, Number 9, November 1998, 1704-1714

http://www.jci.org lymphocytes in the lymphoid tissue, where they ultimately initiate a specific immunological response $(1,2)$. The airways, in particular, are in continuous contact with a large number of airborne particles, both pathogenic and innocuous. Aeroallergens represent a diverse category of antigens which, although nonpathogenic, induce allergic airway inflammation, characterized by a distinct cytokine and immunoglobulin profile, in some individuals (3-7). Therefore, it is of interest to explore the immunological milieu in which an individual can become sensitized to these otherwise innocuous aeroallergens.

Experimental models have shown that under normal circumstances repeated passive exposure to nonpathogenic, protein antigens induces a state of T cell-mediated immunologic tolerance (8-10). Although Renz et al. have described an antigen-specific $\operatorname{IgE}$ response after exposure of mice to aerosolized ovalbumin (OVA), this sensitization regimen per se did not induce the airway eosinophilia characteristic of allergic inflammation (11). Moreover, data from similar models suggest that OVA-specific IgE production is transient and stops spontaneously despite continuation of exposure (for review see reference 12). Therefore, the lungs may be seen as sites of immunologic homeostasis which, it has been argued, are maintained by pulmonary alveolar macrophages whose immunosuppressive activities modulate local T cell responses $(12,13)$. Furthermore, McMenamin et al. hypothesize that $\gamma \delta \mathrm{T}$ cells are implicated in antigen-specific immune suppression that maintains immunologic homeostasis in the lung (9). Nonetheless, despite ongoing immunosuppression in the lungs, some individuals suffer nonprotective, and often severe, airway pathology upon aeroallergen exposure (3-7). Therefore, this paradox hinges on the conditions that disrupt immunologic homeostasis and permit allergic sensitization in the airway.

Bilyk and Holt have demonstrated that the immunosuppressive activity of pulmonary alveolar macrophages could be reversed in vitro by GM-CSF (14). GM-CSF is a member of the hematopoietic cytokine family (15). In addition to its potent effect on hematopoiesis of granulocyte and monocyte lineages, GM-CSF exhibits adjuvant-like properties both in vitro and in vivo (16-22). In vitro, GM-CSF was shown to enhance the primary immune response to sheep red blood cells (16). It activates macrophages derived from bone marrow cultures to synthesize class II MHC molecules and to augment antigen presentation (17). Furthermore, GM-CSF is required to culture dendritic cells (18) and has been shown to upregulate expression of costimulatory molecules on Langerhans cells (19). In animal models, administration of GM-CSF increases the immunogenicity of tumors (20-22), and clinical trials are underway to assess the feasibility of GM-CSF as an adjuvant for tumor vaccination $(23,24)$. That GM-CSF is produced endogenously in the lung in response to various stimuli suggests that GM-CSF, as an immunostimulatory cytokine, may be implicated in allergic sensitization $(25,26)$. 
In this study, we investigated whether GM-CSF could alter the local environment in the lung to promote sensitization to OVA. We show that GM-CSF serves as a potent adjuvant for allergic sensitization to OVA and results in marked peribronchial and perivascular eosinophilic inflammation in the lung. We also describe evidence intimating that this process, which is class II MHC/TcR-dependent and stimulates the expansion of macrophage and dendritic cell populations, induces antigenspecific, T cell-mediated immunity. Therefore, our study describes a mechanism by which the homeostatic balance in the lung is disrupted to permit allergic sensitization.

\section{Methods}

Animals. Female Balb/c mice (6-8 wk old) were purchased from Harlan (Indianapolis, IN). Male and female IL-5 knockout (KO) (27) and corresponding wild-type control mice, and female MHC class II KO mice (28) were bred in-house. The mice were housed under specific pathogen-free conditions after a 12-h light-dark cycle. All experiments described in this study were approved by the Animal Research Ethics Board of McMaster University.

Aerosolization protocol. Over a period of 10 consecutive days (days 0-9), mice were placed in a Plexiglas chamber $(10 \mathrm{~cm} \times 15 \mathrm{~cm} \times$ $25 \mathrm{~cm})$ and exposed for $20 \mathrm{~min}$ daily to aerosolized OVA $(1 \% \mathrm{wt} / \mathrm{vol}$ in $0.9 \%$ saline). The OVA aerosol was produced by a Bennet nebulizer at a flow rate of 10 liters/min. For the rechallenge experiment, mice were exposed to a $1 \%$ OVA aerosol for two 1-h periods separated by $4 \mathrm{~h}$ on day 50 of the protocol.

Administration of adenoviral constructs. To elicit local expression of GM-CSF, a replication-deficient human type 5 adenoviral (Ad) construct carrying murine GM-CSF cDNA in the E1 region of the viral genome was delivered intranasally (i.n.) into anaesthetized animals $24 \mathrm{~h}$ before the first exposure to OVA. Ad/GM-CSF (29) and an E1-deleted control virus (RDA) (30) were administered i.n. at a dose of $3 \times 10^{7} \mathrm{pfu}$ in $30 \mu \mathrm{l}$ of PBS vehicle.

Collection and measurement of specimens. $2 \mathrm{~d}$ after the last OVA exposure (day 11), and at various time points during and after the aerosolization protocol, mice were killed and bronchoalveolar lavage (BAL) was performed as previously described (31). In brief, the lungs were dissected and the trachea was cannulated with a polyethylene tube (Becton Dickinson, Sparks, MD). The lungs were lavaged twice with PBS $(0.25 \mathrm{ml}$ followed by $0.2 \mathrm{ml})$. Approximately $0.3 \mathrm{ml}$ of the instilled fluid was consistently recovered. Total cell counts were determined using a hemocytometer. After centrifugation, supernatants were stored at $-20^{\circ} \mathrm{C}$ for cytokine measurements by ELISA; cell pellets were resuspended in PBS and smears were prepared by cytocentrifugation (Shandon Inc., Pittsburgh, PA) at $300 \mathrm{rpm}$ for $2 \mathrm{~min}$. Diff-Quik (Baxter, McGraw Park, IL) was used to stain all smears. Differential counts of BAL cells were determined from at least 500 leukocytes using standard hemocytological procedures to classify the cells as neutrophils, eosinophils, lymphocytes, or macrophages/monocytes. Additionally, blood was collected by retroorbital bleeding. Serum was obtained by centrifugation after incubating whole blood for $30 \mathrm{~min}$ at $37^{\circ} \mathrm{C}$. Finally, lung tissue was fixed in $10 \%$ formalin and embedded in paraffin. $3-\mu \mathrm{m}$-thick sections were stained with hematoxylin and eosin or Congo red to further identify eosinophils.

Splenocyte culture. Spleens were harvested on day 28 of the aerosolization protocol. Collagenase II (100 U/ml; Worthington Biochemical Corp., Freehold, NJ) in HBSS (Gibco, Burlington, ON, Canada) was injected into the organ, and pieces were incubated in collagenase II $(400 \mathrm{U} / \mathrm{ml})$ for $7 \mathrm{~min}$ at $37^{\circ} \mathrm{C}$. Tissue was triturated between the ends of sterile frosted slides and the resulting cell suspension was filtered through nylon mesh (BSH Thompson, Scarborough, ON, Canada). Red blood cells were lysed with ACK lysis buffer $\left(0.5 \mathrm{M} \mathrm{NH}_{4} \mathrm{Cl}\right.$, $10 \mathrm{mM} \mathrm{KHCO}_{3}$, and $0.1 \mathrm{nM} \mathrm{Na}_{2}$ EDTA at $\mathrm{pH}$ 7.2-7.4), and the splenocytes were washed twice with HBSS and resuspended in RPMI supplemented with 10\% FBS (Gibco), 1\% L-glutamine, and 1\% penicillin/streptomycin. Cells were cultured in medium alone or with $40 \mu \mathrm{g}$ OVA/well at $8 \times 10^{5}$ cells/well in a flat-bottom, 96-well plate (Becton Dickinson, Lincoln Park, NJ). After 5 d of culture, supernatants were harvested for cytokine measurements.

Cytokine and immunoglobulin measurement. ELISA kits for IL-4 and IFN- $\gamma$ were purchased from R\&D Systems (Minneapolis, MN) while the kit for IL-5 was obtained from Amersham (Buckinghamshire, UK). Each of these assays has a threshold of detection of $5 \mathrm{pg} /$ $\mathrm{ml}$. Levels of OVA-specific mouse IgE were detected using an antigen-capture ELISA method that has been described previously (31).

Lung cell isolation and flow cytometric analysis of lung cell subsets. Lungs were cut into small $(\sim 2 \mathrm{~mm}$ diameter) pieces and agitated at $37^{\circ} \mathrm{C}$ for $1 \mathrm{~h}$ in $15 \mathrm{ml}$ of $150 \mathrm{U} / \mathrm{ml}$ collagenase III (Worthington Biochemical Corp.) in HBSS. Using a plunger from a $5-\mathrm{cm}^{3} \mathrm{sy}-$ ringe, the lung pieces were triturated through a metal screen into HBSS, and the resulting cell suspension was filtered through nylon mesh. After lysing red blood cells with ACK lysis buffer, cells were washed once and mononuclear cells were isolated by density centrifugation in 30\% Percoll. Cells were washed twice and stained for flow cytometric analysis. For each antibody combination, $10^{6}$ cells were incubated with monoclonal antibodies at $0-4^{\circ} \mathrm{C}$ for $30 \mathrm{~min}$; the cells were then washed and treated with second stage reagents. Data were collected using a FACScan ${ }^{\circledR}$ and analyzed using PC-LYSYS software (Becton Dickinson, Sunnyvale, CA). The following antibodies and reagents were used: anti-MHC class II, FITC-conjugated M5/114.152 (prepared in-house); anti-B7.1, biotin-conjugated 16-10A1 (PharMingen, Mississauga, ON, Canada); anti-B7.2, biotin-conjugated GLI (PharMingen); anti-CD11b (Mac-1 $\alpha$ ), PE-conjugated M1/70 (PharMingen); anti-CD11c, PE-conjugated HL3 (PharMingen); anti-CD3, biotin-conjugated 145-2C11 (PharMingen); anti-CD4, FITC-conjugated L3T4 (PharMingen); anti-CD8 $\alpha$, FITC-conjugated Ly-2 (PharMingen); anti-CD69, PE-conjugated (PharMingen); and Streptavidin PerCP (Becton Dickinson, San Jose, CA). Titration was used to determine the optimal concentration of each antibody.

Data analysis. Data are expressed as mean \pm SEM, unless otherwise indicated. Whenever suitable, results were interpreted using Student's $t$ test or ANOVA with a Tukey post-hoc test. The difference was considered statistically significant when $P<0.05$.

\section{Results}

Cellular profile in the BAL of mice infected with Ad/GM-CSF (i.n.) and exposed to aerosolized $O V A$. Balb/c mice were infected i.n. with $3 \times 10^{7} \mathrm{pfu} \mathrm{Ad} / \mathrm{GM}-\mathrm{CSF}$ or control virus and subsequently exposed to aerosolized OVA over a period of 10 consecutive days. We have published recently a detailed characterization of GM-CSF transgene expression in the BAL and serum after i.n. delivery of the Ad/GM-CSF construct at the same dose that we have used here (32). In brief, GM-CSF was expressed in the airways for $\sim 10 \mathrm{~d}$, with peak expression of $\sim 80-100 \mathrm{pg} / \mathrm{ml}$ in the BAL at day 7. GM-CSF was undetectable in the serum. $2 \mathrm{~d}$ after the last OVA exposure (day 11), mice were killed and the cellular profile in the BAL was assessed (Fig. 1). Mice exposed to OVA or exposed to OVA in the context of control virus showed no significant changes in BAL cellular profile when compared with naive, untreated mice. Administration of Ad/GM-CSF induced a significant increase in total cell number characterized by an accumulation of mononuclear cells and neutrophils in naive mice at day 11. While exposure to OVA in the context of GM-CSF expression did not alter the quantity of inflammation in terms of total cell number, we observed a qualitative change in the phenotype of the infiltrate; OVA exposure reduced the numbers of mono- 

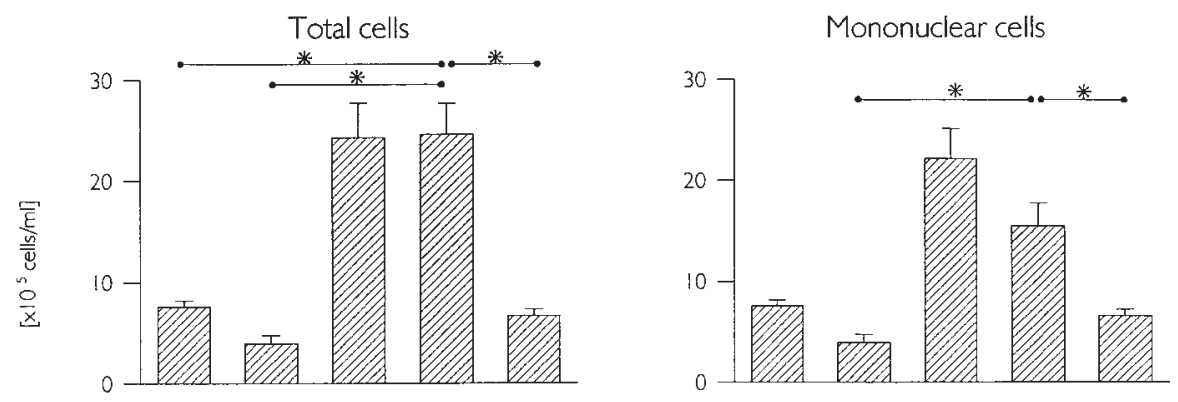

Figure 1. Airway eosinophilia in mice exposed to aerosolized OVA in the context of GM-CSF expression. Over a period of 10 consecutive days, mice were exposed daily to aerosolized OVA. $24 \mathrm{~h}$ before the first exposure, groups of mice were infected with either adenoviral construct expressing GM-CSF (GM) or control virus (RDA).
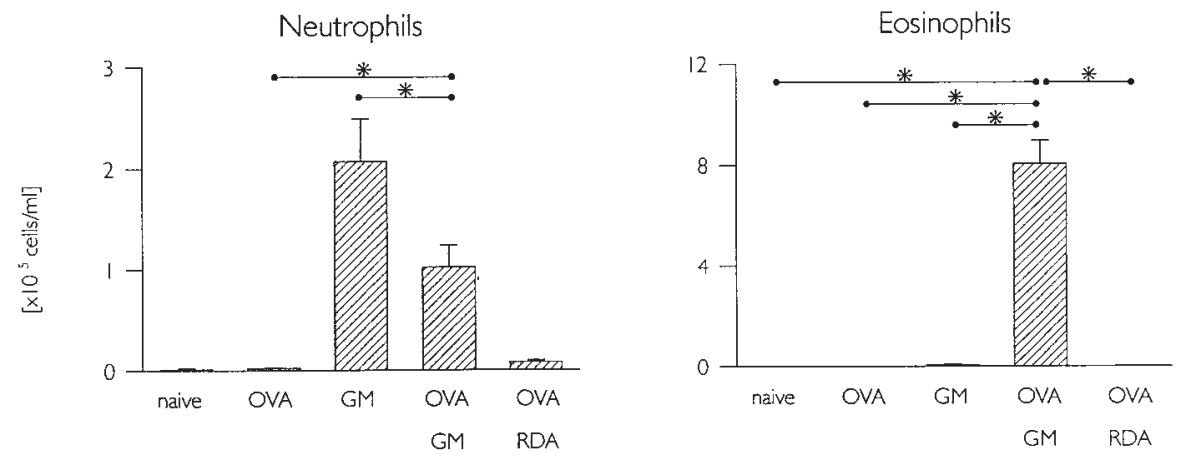

Bars represent untreated mice (naive), OVA-exposed mice $(O V A)$, naive mice infected with Ad/GM-CSF (GM), mice exposed to OVA in the context of Ad/GMCSF (OVA GM), or mice exposed to OVA in the context of an adenoviral infection (OVA RDA). Data show total cell number, mononuclear cells, neutrophils, and eosinophils in BAL obtained $48 \mathrm{~h}$ after the last OVA aerosol exposure (mean $\pm \mathrm{SEM} ; n=$ 6-14; statistical analysis was performed using ANOVA with Tukey post-hoc test; $* P<0.05)$.

nuclear cells and neutrophils in the BAL, while significantly increasing the number of eosinophils.

Histological evaluation of lung tissue obtained from mice exposed to $O V A$ in the presence of GM-CSF. We conducted a detailed histological evaluation that showed a correlation between events occurring in the tissue and the findings in the BAL. As shown in Fig. $2 A$, lungs of mice exposed to OVA alone exhibited no inflammatory infiltrate in the peribronchial or perivascular regions. Infection with $\mathrm{Ad} / \mathrm{GM}-\mathrm{CSF}$ led to mild to moderate inflammation in the lung tissue. Inflammation was principally peribronchial in nature (Fig. $2 B$ ) and was characterized by mononuclear cells, neutrophils, and an absence of eosinophils (Fig. $2 \mathrm{C}$ ). Repeated exposure to OVA aerosol in the context of Ad/GM-CSF resulted in a marked accumulation of inflammatory cells both perivascularly and peribronchially (Fig. $2 \mathrm{D}$ ), with evidence of goblet cell hyperplasia and mucous secretion into the lumen of the airway (Fig. $2 E$ ). The inflammatory infiltrate was eosinophilic (Fig. $2 F$ ). Therefore, histological evaluation confirmed the findings in the BAL: development of airway eosinophilia in this model required aeroallergen exposure in the context of GM-CSF expression.

Time course of eosinophil infiltration into the airway. We assessed the time course of eosinophil infiltration into the bronchoalveolar compartment. Mice were infected i.n. with $\mathrm{Ad} /$ GM-CSF and/or exposed daily to aerosolized OVA. At the indicated time points during the 10 -d aerosolization protocol, mice were killed and the cellular profile in the BAL was determined. Fig. 3 shows that at no time point were eosinophils detected in mice exposed to OVA alone or infected with $\mathrm{Ad} /$ GM-CSF alone. In mice exposed to OVA in the context of GM-CSF, infiltration of eosinophils was first observed in the BAL at day 6 and increased thereafter; the eosinophil population peaked between days 11 and 14. There is a high SEM at day 14 because resolution of eosinophilia had begun in some, but not all, mice. Airway inflammation was completely resolved in all mice by day 28 .

Endogenous production of IL-4, IL-5, and OVA-specific $\operatorname{Ig} E$. Previously, we have reported in a murine model of antigen-induced airway inflammation that airways eosinophilia is preceded by a transient increase in Th2 cytokines (31). Therefore, we investigated whether the eosinophilic inflammation observed in mice receiving both GM-CSF and repeated OVA exposures was preceded by an increase in IL-4 and IL-5. Table I shows that IL-5 was detected in both serum and BAL as early as day 6 , with peak levels at day 7 . In the BAL we observed prolonged expression of IL-5 until day 9; whereas, in the serum, IL-5 levels declined at day 8. Note that peak IL-5 expression preceded maximal infiltration of eosinophils into the air-

Table I. Cytokine Levels in Serum and BAL

\begin{tabular}{cccc}
\hline Days & IL-5 BAL & IL-5 serum & IL-4 BAL \\
\hline & $p g / m l$ & $p g / m l$ & $p g / m l$ \\
Naive & UD & UD & UD \\
4 & UD & UD & UD \\
6 & $18 \pm 13$ & $39 \pm 29$ & $6 \pm 7$ \\
7 & $178 \pm 94$ & $181 \pm 46$ & $18 \pm 15$ \\
8 & $136 \pm 44$ & $24 \pm 6$ & $22 \pm 15$ \\
9 & $100 \pm 5$ & $25 \pm 7$ & $46 \pm 18$ \\
10 & $13 \pm 3$ & UD & UD \\
11 & UD & UD & UD \\
& & & \\
\hline
\end{tabular}

Mice were infected i.n. with $3 \times 10^{7}$ pfu Ad/GM-CSF 16 h before daily exposures to OVA aerosol. At the indicated time points during the aerosolization protocol, cytokine levels were determined in serum and BAL. Values represent mean $\pm \mathrm{SD} ; n=3-6$. UD, undetectable. 

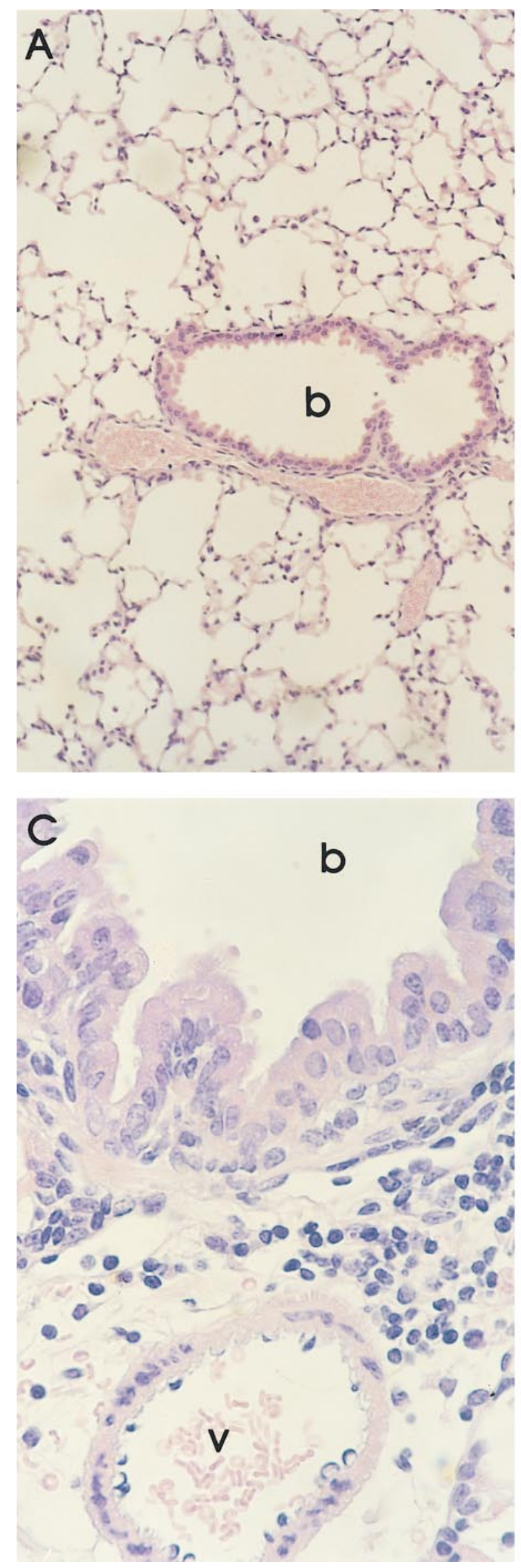
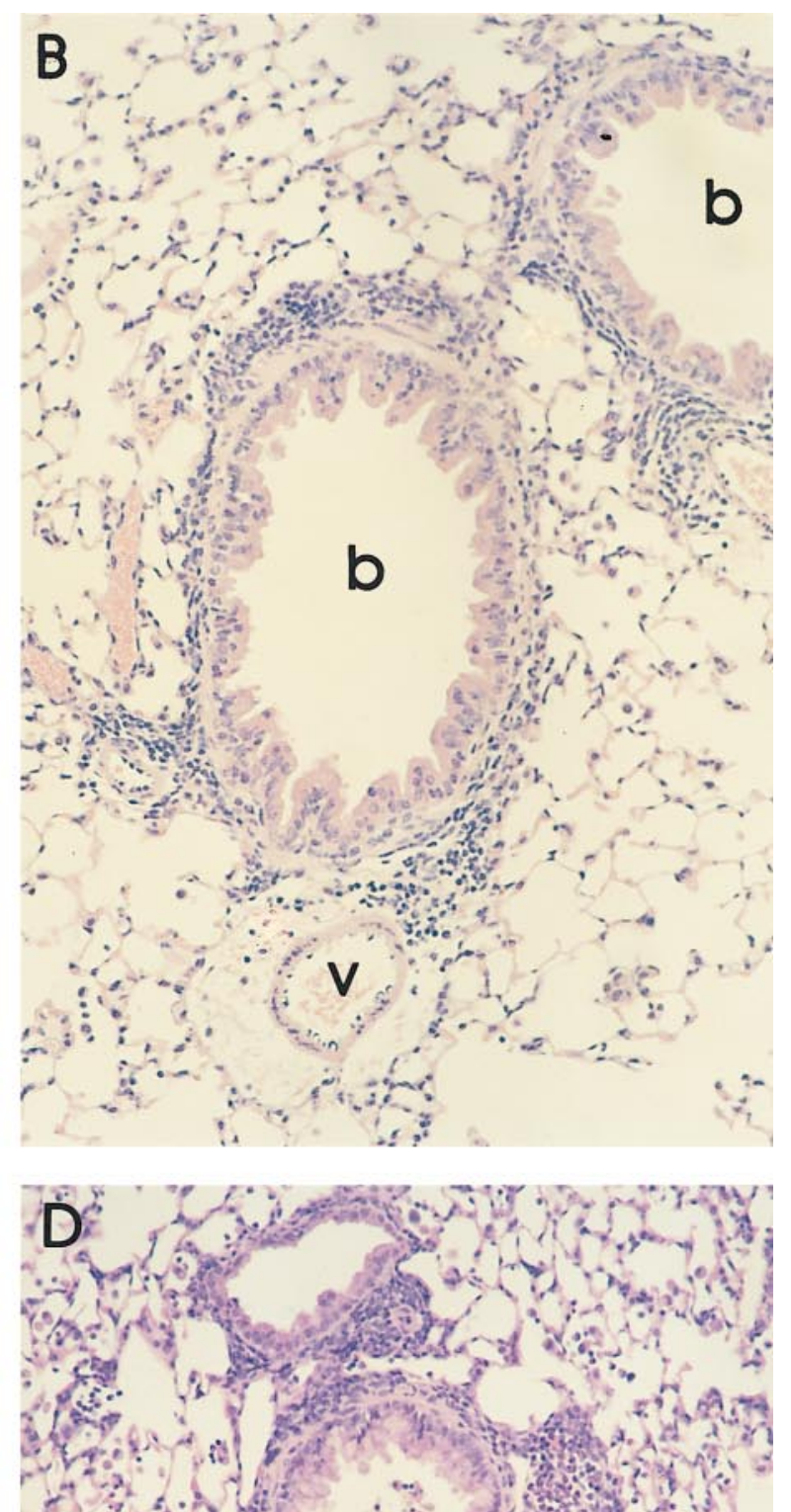

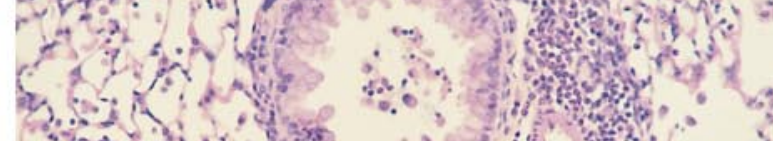

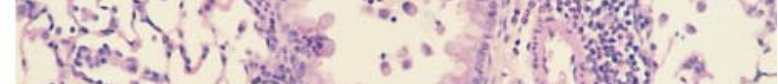

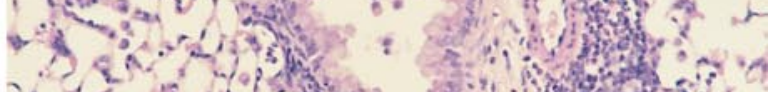

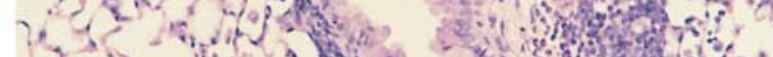

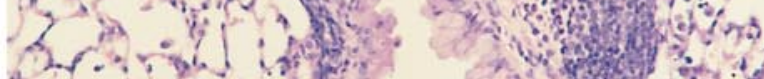

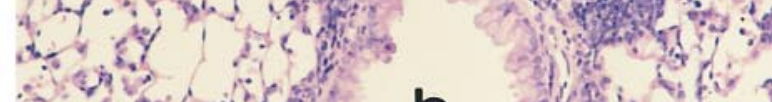

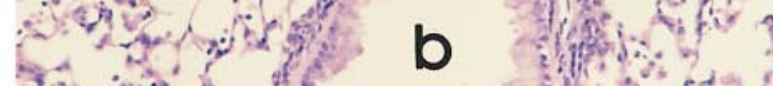

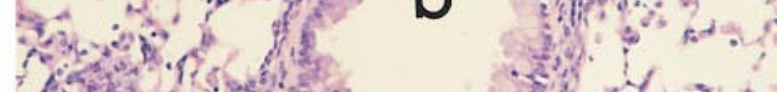

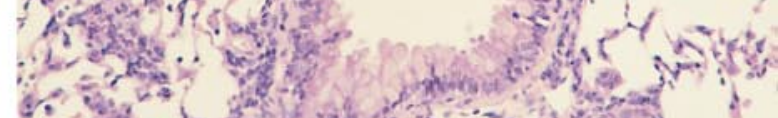
4. Henters

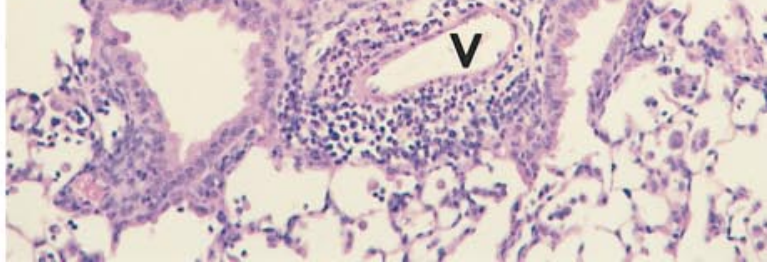



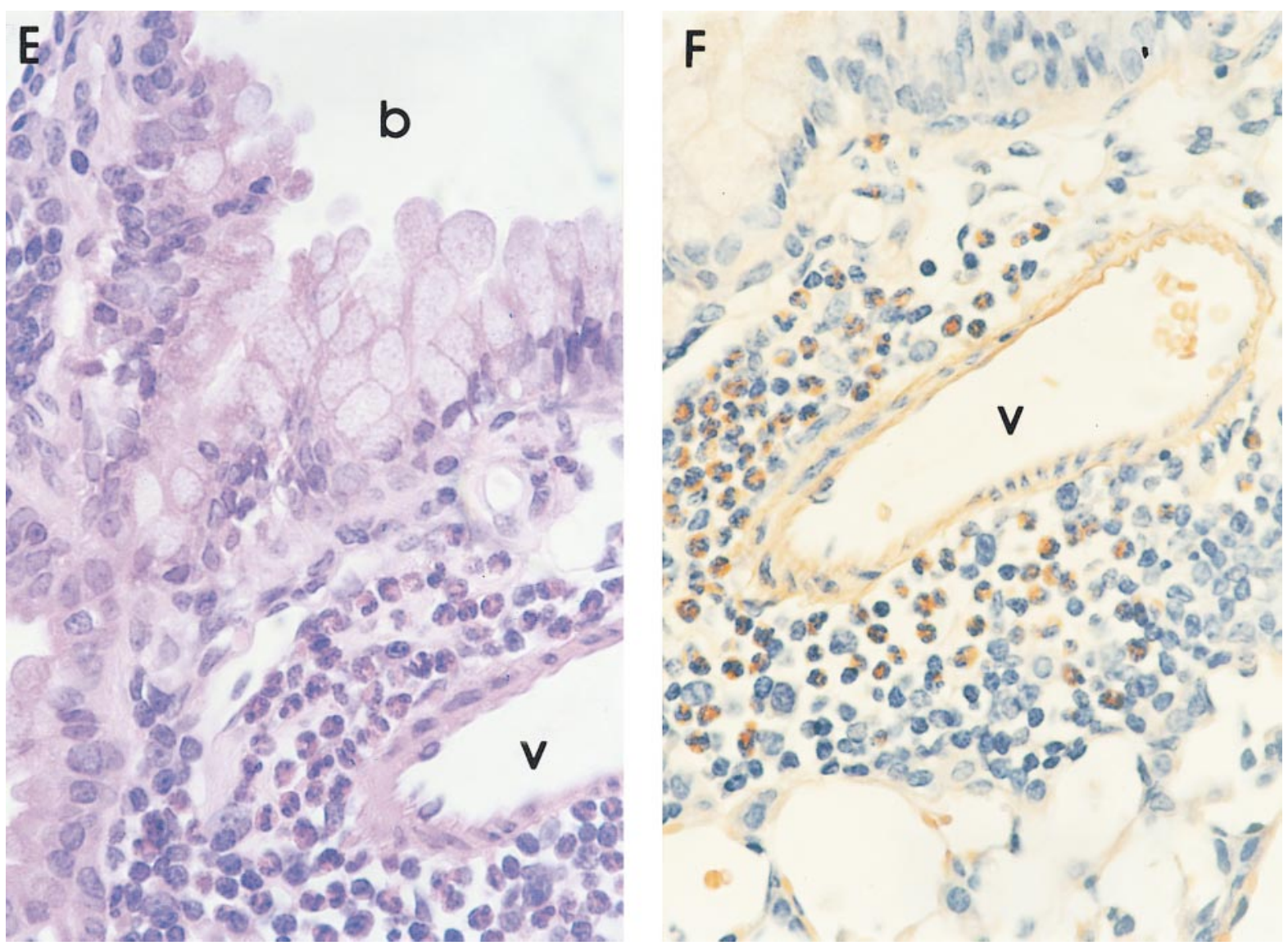

Figure 2. Light photomicrograph of paraffin-embedded sections of lung tissues. Over a period of 10 consecutive days, mice were exposed for 20 min daily to aerosolized OVA. All tissues were obtained at day 11, i.e., $48 \mathrm{~h}$ after the last OVA exposure. Panels represent exposure to OVA alone $(A)$, infection with Ad/GM-CSF alone $(B$ and $C)$, and repeated exposure to OVA aerosol in the context of GM-CSF expression $(D-F)$. $A-E$ show sections stained with hematoxylin and eosin; the section in $F$ was stained with Congo red. In particular, note the absence of eosinophils and ciliated epithelium in $C$, eosinophilic infiltrate and goblet cell hyperplasia in $E$, and eosinophils (brown) in $F$. Magnification of panels: $A, \times 200 ; B, \times 160 ; C, \times 640 ; D, \times 160 ; E, \times 640 ;$ and $F, \times 640$.

way. Low levels of IL-4 were detected in the BAL between days 6 and 9. We were unable to detect IL-4 in the serum. Neither IL-4 nor IL-5 was detected in mice exposed to OVA only or infected with Ad/GM-CSF. In addition, we observed no OVA-specific IFN- $\gamma$ induction in mice exposed to OVA in the context of GM-CSF.

We also assessed whether repeated exposure to OVA in the context of GM-CSF expression induces production of antigen-specific IgE. No OVA-specific IgE was detected in mice exposed to OVA or infected with Ad/GM-CSF alone. 4.5 \pm 2.8 $\mathrm{U} / \mathrm{ml}$ of OVA-specific IgE (mean $\pm \mathrm{SD} ; n=12)$ was detected in mice exposed to aerosolized OVA in the context of GM-CSF at day 11 and remained elevated for a prolonged period of time (day 50). Peculiarly, these levels of OVA-specific IgE are 50100 -fold lower than levels detected in mice sensitized intraperitoneally with OVA adsorbed to aluminum hydroxide (31).

Antigen-induced airway inflammation is IL-5 and class II MHC dependent. Previous reports have demonstrated clearly that IL-5 is critical for the development of airway eosinophilia $(27,33)$. Therefore, we investigated whether airway eosinophilia in mice exposed to OVA in the presence of GM-CSF were IL-5-dependent. To this end, IL-5 KO mice were infected i.n. with Ad/GM-CSF and subsequently exposed to
OVA as described above. $2 \mathrm{~d}$ after the last exposure, mice were killed and the cellular profile in the BAL was evaluated. Fig. 4 (top) shows that in IL-5 KO mice airway eosinophilia decreased by $>95 \%$ when compared with control littermates (hatched bars). These control mice developed eosinophilic airway inflammation similar to that observed in the Balb/c strain; likewise, no inflammation was detected in control mice exposed to OVA alone. These observations lend compelling support to the hypothesis that IL-5 is essential for the generation of airway eosinophilia, even in the context of GM-CSF transgene expression.

Next, we assessed whether airway eosinophilia induced by GM-CSF and OVA were antigen-driven, i.e., whether this response required class II MHC expression and the presence of class II-restricted CD4 T cells. We infected class II MHC KO mice and C57BL/6 control mice with Ad/GM-CSF and exposed them to aerosolized OVA. Fig. 4 (bottom) shows that no airway eosinophilia developed in class II MHC KO mice, a result that supports a putative role for antigen presentation and MHC class II-restricted $\mathrm{T}$ cells in the inflammatory process. Therefore, we speculate that GM-CSF activates antigen presentation in the airway and thereby facilitates a T cell-mediated response to OVA. 


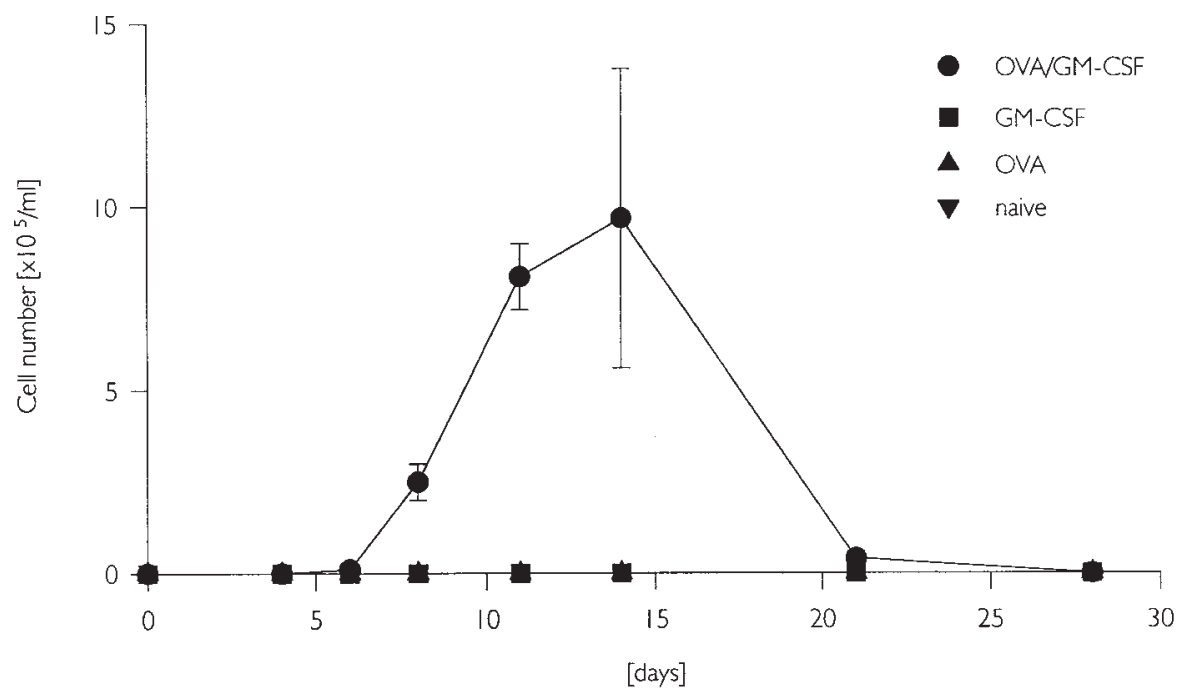

Figure 3. Time course of eosinophil infiltration into the bronchoalveolar space. Mice were exposed to aerosolized OVA daily in the context of GM-CSF expression. At the indicated time points during the 10-d aerosolization protocol, the cellular profile in the BAL was determined. Groups represented include untreated (naive), OVA-exposed (OVA), Ad/GM-CSFinfected only $(G M-C S F)$, and Ad/GM-CSFinfected, OVA-exposed (OVA/GM-CSF) mice. Data show eosinophils in BAL (mean \pm SEM; $n=3-14$ ).
Increase in dendritic cell, macrophage, and T lymphocyte populations in the lung. We used flow cytometric analysis of dispersed lung cells to explore whether exposure to OVA in a GM-CSF milieu affects populations of APCs; in particular, dendritic cells (class II MHC bright, CD11 $c^{\text {bright }}$ ) (34) and macrophages (class II MHC ${ }^{\text {bright }}$, Mac-1 ${ }^{\text {bright }}$ ) (35) were examined. The top of Fig. 5 shows that dendritic cells and macrophages were detected in similar numbers in naive and OVA-exposed mice at day 7 of the aerosolization protocol. Infection with $\mathrm{Ad} /$ GM-CSF led to an increase in dendritic cells and macrophages, an effect that was amplified in mice exposed to OVA in the context of GM-CSF. In addition, dendritic cells and macrophages in these mice expressed the costimulatory molecules
B7.1 and B7.2 (Table II). These data, in conjunction with the class II MHC KO results, are consistent with the hypothesis that GM-CSF enhances antigen presentation and therefore evokes a specific $\mathrm{T}$ cell response to the OVA antigen. To this end, the bottom of Fig. 5 shows an expansion of both CD4 and CD8 T cells in the lungs of mice receiving both OVA and Ad/ GM-CSF. To assess the activation status of these T cells, we stained for CD69 expression, a putative marker of early $\mathrm{T}$ cell activation (36). Table III shows that exposure to OVA in the context of GM-CSF induced the activation of both T cell subtypes, an observation that points to the involvement of $\mathrm{T}$ cells in the potentiation of this response.

In vivo rechallenge of mucosally sensitized mice. A further
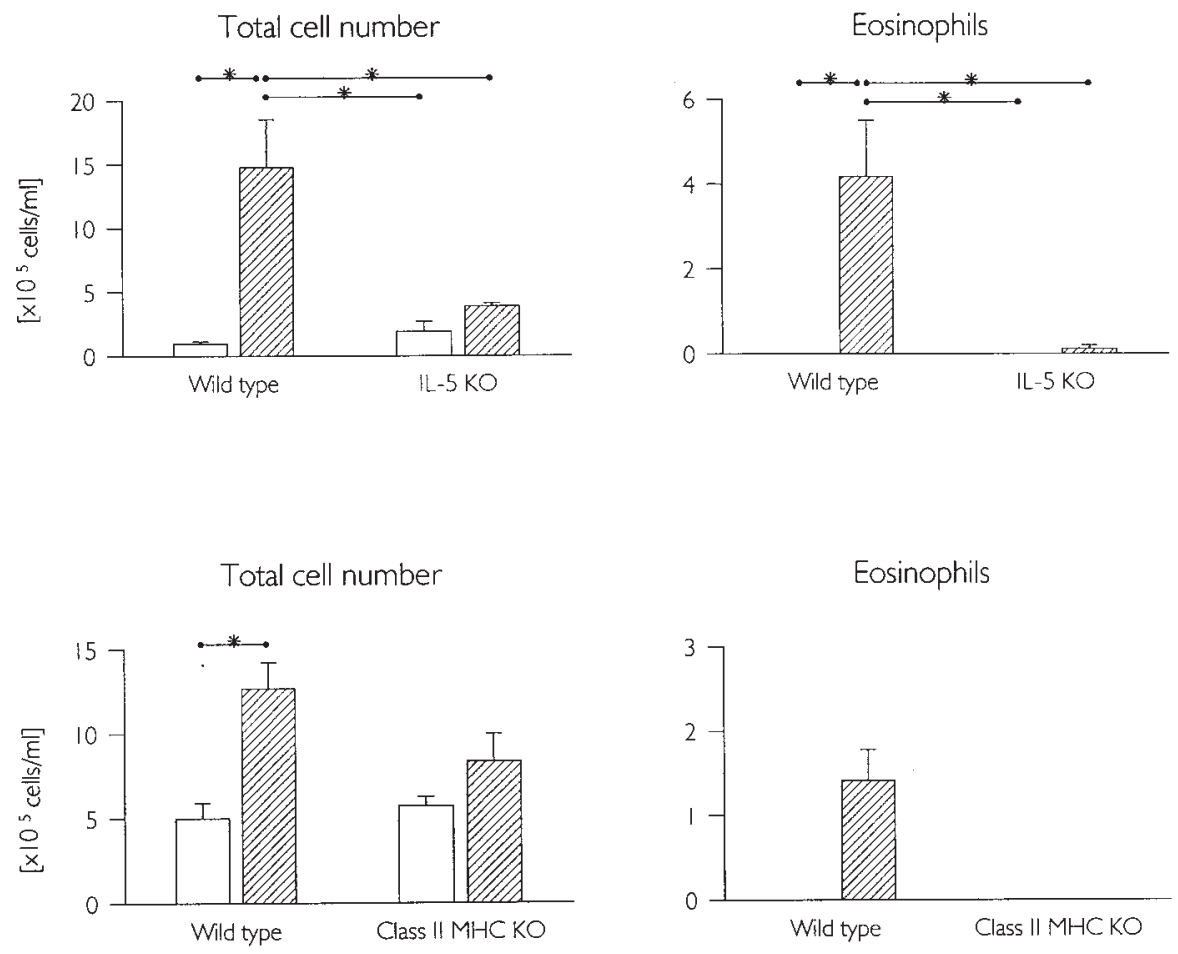

Figure 4. Antigen-induced airway inflammation in IL-5 and class II MHC KO mice. Over a period of 10 consecutive days, IL-5 and class II MHC KO mice were exposed daily to aerosolized OVA alone (open bars) or in the context of GM-CSF expression. The top panels represent IL-5 KO mice; the bottom panels represent class II MHC KO mice. Data show total cell number and eosinophils in BAL obtained $48 \mathrm{~h}$ after the last OVA aerosol exposure (mean \pm SEM; $n=2-6$; statistical analysis was performed using ANOVA with Tukey post-hoc test; $* P<0.05)$. 

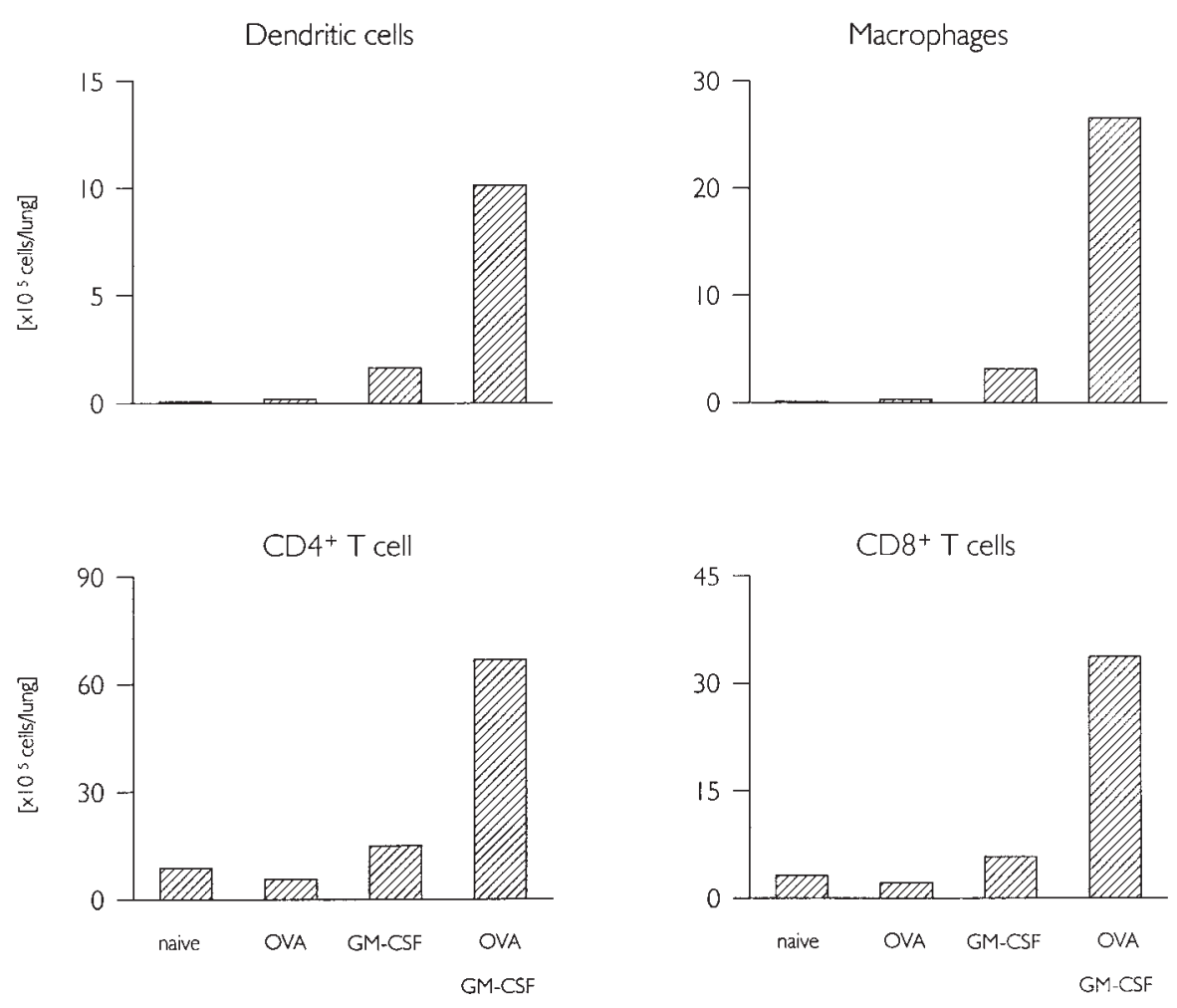

Figure 5. Flow cytometric analysis of macrophage, dendritic cell, and T cell populations in the lung tissue. Dendritic cells and macrophages were analyzed in lung cell homogenates at day 7 , whereas $T$ lymphocyte subsets were assessed at day 11. 50,000 events were collected and analyzed for class II MHC ${ }^{\text {bright }} / \mathrm{CD} 11 \mathrm{c}^{\text {bright }}$ (dendritic cells) and class II MHC ${ }^{\text {bright }} / \mathrm{Mac}-1^{\text {bright }}$ (macrophages), or $\mathrm{CD}^{+} / \mathrm{CD}^{+}{ }^{+} \mathrm{T}$ cells and $\mathrm{CD}^{+} / \mathrm{CD}^{+} \mathrm{T}$ cells. Data represent untreated control mice (naive), OVA-exposed mice $(O V A)$, mice expressing GM-CSF $(G M-C S F)$, and mice exposed to OVA in the context of GM-CSF expression (OVA $G M-C S F)$; lung cells from three to eight mice were pooled for each group. piece of evidence to support the hypothesis of antigen-specific immunity is the demonstration of antigen-specific memory. Therefore, at day 50, after complete resolution of airway eosinophilia (Fig. 3), we reexposed mice to aerosolized OVA for $1 \mathrm{~h}$ on two occasions $4 \mathrm{~h}$ apart; this challenge protocol has been used in conventional models of antigen-induced airway inflammation $(31,37)$. 2 d later mice were killed and the cellular profile of the BAL was assessed. Mice initially exposed to OVA alone did not develop airway eosinophilia upon reexposure (Fig. 6), whereas mice exposed to OVA in the presence of GM-CSF developed airway eosinophilia after rechallenge. The cellular profile in the BAL was characterized by increased

Table II. Expression of Costimulatory Molecules (B7.1/B7.2) on Dendritic Cells and Macrophages

\begin{tabular}{|c|c|c|c|c|}
\hline & \multicolumn{2}{|c|}{ Dendritic cells } & \multicolumn{2}{|c|}{ Macrophages } \\
\hline & B7.1 & B7.2 & B7.1 & B7.2 \\
\hline & \multicolumn{2}{|c|}{$\times 10^{5} \mathrm{celll} / \mathrm{lung}$} & \multicolumn{2}{|c|}{$\times 10^{5}$ cells/lung } \\
\hline Naive & 0.05 & 0.05 & 0.04 & 0.02 \\
\hline OVA & 0.10 & 0.06 & 0.12 & 0.06 \\
\hline GM-CSF & 0.89 & 0.55 & 1.54 & 0.83 \\
\hline OVA/GM-CSF & 3.96 & 2.92 & 7.92 & 4.45 \\
\hline
\end{tabular}

Mice were exposed daily to aerosolized OVA in the context of GM-CSF expression. After seven exposures, mice were killed, lungs were pooled (4-8 per group), and costimulatory molecule expression in lung cell homogenates was assessed by flow cytometry. 50,000 events were collected, and cells expressing class II MHC $\mathrm{M}^{\text {bright }}, \mathrm{CD} 11 \mathrm{c}^{\text {bright }}$ (dendritic cells) or class II MHC ${ }^{\text {bright }}$, Mac- $1^{\text {bright }}$ (macrophages) were analyzed for expression of B7.1 and B7.2. numbers of all cell types, and of eosinophils in particular. This OVA-specific in vivo recall was mirrored in vitro. Splenocytes derived from mice exposed to OVA in the presence of GMCSF produced IL-4 and IL-5 upon stimulation with OVA (Fig. 7). Taken together, these findings confirm that exposure to OVA in the presence of GM-CSF generated antigen-specific memory, and suggest strongly that specific $\mathrm{T}$ cells generated upon mucosal sensitization circulated systemically.

\section{Discussion}

By necessity, the lungs are under constant exposure to aeroallergens. These agents are innocuous and do not induce pathology in most individuals. However, epidemiological stud-

Table III. Expression of Early Activation Marker CD69 on CD4 and CD8 T Cells

\begin{tabular}{lcc}
\hline & CD4 T cells & CD8 T cells \\
\hline & \multicolumn{2}{c}{$\times 10^{5}$ cells/lung (\%) } \\
Naive & $0.08(1)$ & $0.03(1)$ \\
OVA & $0.06(2)$ & $0.02(1)$ \\
GM-CSF & $0.77(7)$ & $0.33(8)$ \\
OVA/GM-CSF & $10.24(29)$ & $5.48(30)$ \\
& &
\end{tabular}

Mice were exposed daily to aerosolized OVA in the context of GM-CSF expression. On day 11, mice were killed, the lungs were pooled (3-6 per group), and CD69 expression in lung cell homogenates was assessed by flow cytometry. 50,000 events were collected, and cells expressing CD3 and $\mathrm{CD} 4$ or $\mathrm{CD} 8$ were analyzed for CD69 expression. 

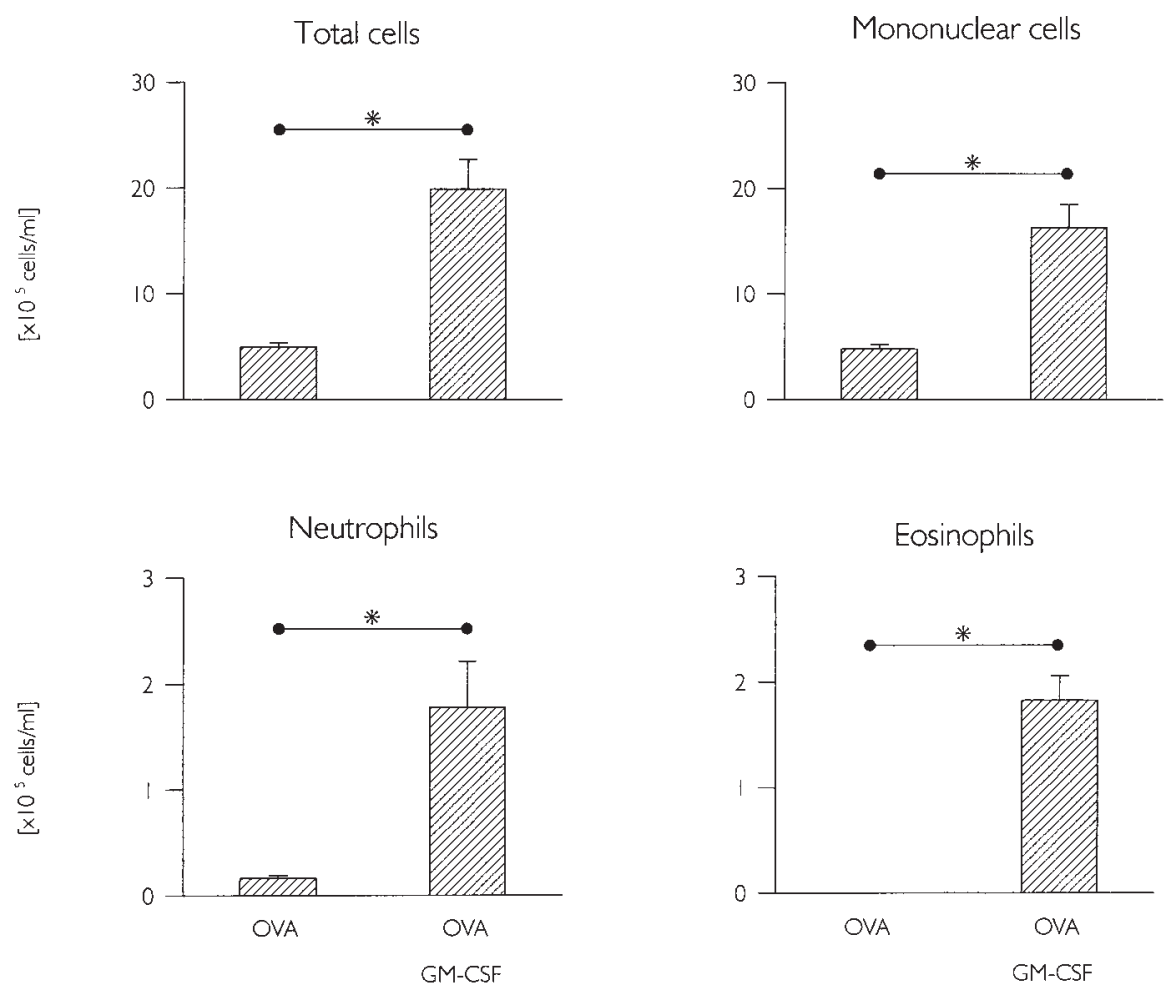

Figure 6. In vivo rechallenge of mice exposed to OVA in the context of GM-CSF. At day 50, after complete resolution of the initial airway inflammation, mice were reexposed to aerosolized OVA. Data represent mice initially exposed either to OVA alone or to OVA in the context of GM$\mathrm{CSF}$ (mean \pm SEM; $n=3$; statistical analysis was performed using Student's $t$ test; $* P<0.05)$.

ies have shown that, in a growing percentage of the population, allergen exposure results in severe airway inflammation $(38,39)$. This inflammation is thought to be mediated by a specific immune response to allergens, and is characterized by the expression of a distinct $\mathrm{Th} 2$ cytokine profile, particularly IL- 5 and IL-4, and by the development of antigen-specific $\operatorname{IgE}$ $(6,7)$. Therefore, the conundrum facing researchers is to explain why some individuals mount a type 2 allergic response that can induce often serious airway pathology, while others do not. On the one hand, it could be argued that genetics can predispose individuals to allergic disease; on the other, epidemiological studies suggest that environmental influences should not be dismissed. Moreover, it has been well established that mucosal surfaces, such as the lung, have immunosuppressive capacity $(1,8-10,12)$. Indeed, in experimental models it has been shown that exposure to aerosolized OVA does not lead to the development of airway histopathology (11), but may in fact elicit the phenomenon known as inhalation tolerance (12). Therefore, we have begun to investigate the immunologic milieu in the lung that permits allergic sensitization; specifically we explored whether GM-CSF, a cytokine with known adjuvant-like properties, would promote allergic sensitization to OVA and lead to histopathologic changes in the lung (16-22).

We used an adenoviral-based gene transfer approach to express GM-CSF in lung tissue (29). This approach has advantages over the use of recombinant cytokines in that a transgene can be expressed in a dose-dependent manner in a specific tissue for an extended period of time. However, expression is transient and avoids the pathology observed in transgenic mice. For example, mice transgenic for generalized expression of GM-CSF develop a fatal syndrome of tissue damage (40). We used a low infectious dose of the adenoviral construct
IL-4
IL-5

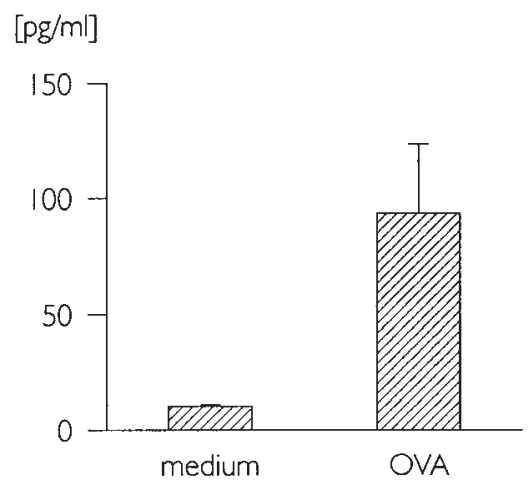

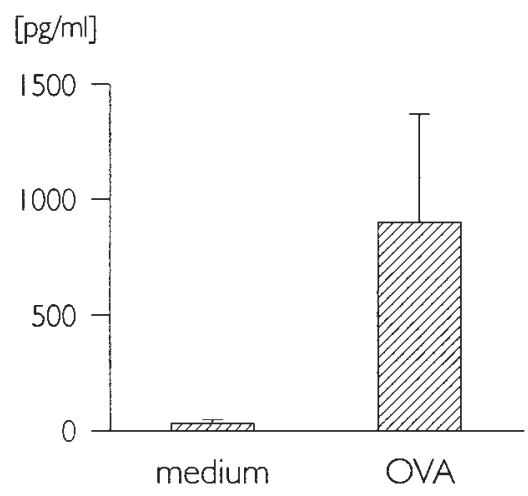

Figure 7. In vitro antigen-specific IL-4 and IL-5 production by splenocytes. Splenocytes were obtained from mice exposed to OVA in the context of GM-CSF expression. Cells were cultured in medium alone or stimulated with OVA (mean \pm SEM; $n=3$ ). 
since we have reported previously that a high dose of Ad/GMCSF leads to eosinophilia, monocytosis, and fibrotic reactions in rat lungs (29). We expressed GM-CSF in the lung for $\sim 10 \mathrm{~d}$, with peak expression of $80-100 \mathrm{pg} / \mathrm{ml}$ in the BAL at day 6 of the protocol. We consider this to be physiologically relevant since we have detected similar levels in the BAL after antigen challenge in a murine model of antigen-induced airway inflammation (31).

Extended (10-d) expression of low levels of GM-CSF induced mild to moderate tissue inflammation, which was mainly mononuclear in nature and localized around the airways. This inflammatory response was significantly altered when the mice were exposed repeatedly to aerosolized OVA. We observed in the lung tissue an eosinophilic inflammatory cell infiltrate that was perivascular and peribronchial, with evidence of goblet cell hyperplasia. Tissue eosinophilia and goblet cell hyperplasia were accompanied by a transient rise in the Th2 cytokines IL-4 and IL-5. Interestingly, peak levels of IL-5 in the serum and the BAL preceded maximal airway eosinophilia by $\sim 4 \mathrm{~d}$. That IL-5 has been implicated in eosinopoiesis and tissue eosinophilia $(27,33)$ led us to hypothesize that there was a causal relationship between IL-5 production and airway eosinophilia in our model. Using IL-5 KO mice, we demonstrated that the observed airway eosinophilia induced by repeated OVA exposure in the context of GM-CSF critically required IL-5.

The observed changes in the lung resolved completely. After resolution of airway inflammation, a single exposure to aerosolized OVA readily reconstituted airway eosinophilia. Furthermore, splenocytes derived from mice exposed to OVA in a GM-CSF milieu produced IL-4 and IL-5 after in vitro stimulation with OVA. These observations are indicative of an OVA-specific immune response that resulted in antigen-specific memory. From the perspective of mechanism, we hypothesized that GM-CSF expression enhanced antigen presentation capacity in the lung and therefore facilitated allergic sensitization. At day 7, we observed a marked increase in dendritic cells and macrophages in the lungs of mice expressing GM-CSF; these macrophages and dendritic cells expressed the costimulatory molecules B7.1 and B7.2. Moreover, flow cytometric analysis of $\mathrm{T}$ lymphocyte subsets showed not only an expansion of CD4 and CD8 T cells in mice treated with $\mathrm{Ad} /$ GM-CSF and OVA, but also an upregulation of the early activation marker $\mathrm{CD} 69$ when compared with mice exposed to OVA alone or infected with Ad/GM-CSF. The expression of this cell surface glycoprotein, in particular, is indicative of $\mathrm{T}$ cell activation, and therefore of an antigen-specific response (for review see reference 36). It would seem, then, that GMCSF serves as an adjuvant that creates an environment in which an otherwise innocuous agent can induce a $\mathrm{T}$ celldriven, inflammatory immune response. This principle has been applied in cancer vaccination strategies, in which GMCSF facilitates a protective immune response against cancer antigens with otherwise low immunogenicity (20-22). However, in contrast to the desirable immune response observed in cancer therapy, in our model GM-CSF renders an otherwise innocuous antigen pathogenic, presumably through a Th2 mechanism.

The role of the antigen, namely OVA, in this process is unequivocal. IL-4 and IL-5 production was detected only in $\mathrm{Ad} /$ GM-CSF-infected mice that were subsequently exposed to OVA. Moreover, the elevated number of dendritic cells and macrophages in the lungs of Ad/GM-CSF-treated mice was further increased in mice exposed to aerosolized OVA. This is likely due to a synergistic effect between GM-CSF and Th2 cytokines detected in OVA-exposed mice. Indeed, it has been shown in vitro that the combination of GM-CSF and IL-4 is required for optimal expansion of dendritic cells (18). Therefore, it would seem that these mice have an increased capacity to present antigen. Consistent with this hypothesis, the inflammatory process critically required the interaction between class II MHC and T cells; we observed no airway eosinophilia in mice deficient in class II MHC. That we observed an upregulation of CD69, as well as an expansion of T cell populations, in mice treated with Ad/GM-CSF and OVA further supports the contention that this is an antigen-driven response. Therefore, in the context of GM-CSF expression, OVA initiates a cascade of events that expands both APC and OVA-specific T cell populations, and ultimately results in tissue pathology. These findings underscore the importance of both antigen and immunologic milieu in the induction of a specific immune response (41).

That GM-CSF is produced endogenously in the lung suggests that our model may reflect actual physiologic processes. It has been reported previously that GM-CSF is secreted by airway epithelial and endothelial cells $(25,42,43)$, lung fibroblasts $(26,44)$, and macrophages (45) in response to various stimuli. Therefore, exposure to allergen in the context of stimuli that induce GM-CSF expression may promote allergic sensitization and eosinophilic inflammation in the airways. Moreover, viruses such as RSV and rhinovirus have been implicated in the induction and exacerbation of asthma $(46,47)$. Although the role of GM-CSF in the induction of allergic sensitization during virus infection remains speculative, experimental models support this hypothesis. Sakamoto et al. (48) and Holt et al. (49) have reported that allergic sensitization can be elicited during the acute phase of influenza virus infection, whereas exposure to allergen alone did not induce sensitization. Furthermore, expression of GM-CSF was reported in mild asthmatics (50) and in patients with nasal polyps (51). Generally, GMCSF is associated with an enhancement of eosinophil survival. Additionally, GM-CSF might promote antigen presentation, thereby driving the activation of allergen-specific T cells. Our data suggest that GM-CSF is involved in this process.

In summary, we have shown that exposure to OVA in the context of GM-CSF induces airway eosinophilia, tissue pathology, and OVA-specific memory. This profile contrasts sharply with the results of OVA exposure alone, which does not lead to airway histopathology and, as others have proposed, may induce inhalation tolerance $(8-10,12)$. Situations that result in elevated GM-CSF expression may disrupt this homeostatic balance and create conditions conducive to allergic sensitization. Therefore, our findings may contribute to an enhanced understanding of the immunopathogenesis of allergic diseases.

\section{Acknowledgments}

We extend our appreciation to Drs. Klaus Matthaei and Ian Young (The John Curtin School of Medical Research, The Australian National University) for allowing us to use their IL-5 KO mice in this study. The excellent technical help of Susanna Goncharova, Duncan Chong, and Xueya Feng, and the secretarial assistance of Mary Kiriakopoulos are gratefully acknowledged.

This work was funded in part by the Medical Research Council (Canada) and by Astra Draco AB (Lund, Sweden). M.R. Stämpfli holds a fellowship from the Medical Research Council/Canadian 
Lung Association, Z. Xing holds an MRC scholarship, and M. Jordana is a Career Scientist of the Ontario Ministry of Health.

\section{References}

1. Jansen, H.M. 1996. The role of alveolar macrophages and dendritic cells in allergic airways sensitization. Allergy. 51:279-292.

2. Bienenstock, J. 1984. Bronchus-associated lymphoid tissue. In Immunology of the Lung and Upper Respiratory Tract. J. Bienenstock, editor. McGrawHill Book Co., Montreal. 96-118.

3. Bradley, B.L., M. Azzawi, M. Jacobson, B. Assoufi, J.V. Collins, A.M. Irani, L.B. Schwartz, S.R. Durham, P.K. Jeffery, and A.B. Kay. 1991. Eosinophils, T-lymphocytes, mast cells, neutrophils and macrophages in bronchial biopsy specimens from atopic subjects with asthma: comparison with biopsy specimens from atopic subjects without asthma and normal control subjects and relationship to bronchial hyperresponsiveness. J. Allergy Clin. Immunol. 88: 661-674.

4. Djukanovic, R., W.R. Roche, J.W. Wilson, C.R.W. Beasley, O.P. Twentyman, P.H. Howarth, and S.T. Holgate. 1990. Mucosal inflammation in asthma. Am. Rev. Respir. Dis. 142:434-457.

5. Corrigan, C.J., and A.B. Kay. 1992. T cells and eosinophils in the pathogenesis of asthma. Immunol. Today. 13:501-507.

6. Robinson, D.S., Q. Hamid, S. Ying, A. Tricopoulos, J. Barkans, A.M. Bentley, C. Corrigan, S.R. Durham, and A.B. Kay. 1992. Predominant Th2-like bronchoalveolar T-lymphocyte population in atopic asthma. N. Engl. J. Med. 326:298-304.

7. Bentley, A.M., Q. Meng, D.S. Robinson, Q. Hamid, A.B. Kay, and S.R. Durham. 1993. Increases in activated T lymphocytes, eosinophils and cytokine mRNA expression for interleukin-5 and granulocyte/macrophage colony-stimulating factor in bronchial biopsies after allergen inhalation challenge in atopic asthmatics. Am. J. Respir. Cell Mol. Biol. 8:35-42.

8. McMenamin, C., and P.G. Holt. 1993. The natural immune response to inhaled soluble protein antigens involves major histocompatibility complex (MHC) class I-restricted $\mathrm{CD}^{+} \mathrm{T}$ cell-mediated but $\mathrm{CD}^{+} \mathrm{T}$ cell-dependent immune deviation resulting in selective suppression of immunoglobulin E production. J. Exp. Med. 178:889-899.

9. McMenamin, C., C. Pimm, M. McKersey, and P.G. Holt. 1994. Regulation of $\mathrm{IgE}$ responses to inhaled antigen in mice by antigen-specific $\gamma \delta \mathrm{T}$ cells. Science. 265:1869-1871.

10. van Halteren, A.G., M.J. van der Cammen, D. Cooper, H.F. Savelkoul, G. Kraal, and P.G. Holt. 1997. Regulation of antigen-specific IgE, IgG1, and mast cell responses to ingested allergen by mucosal tolerance induction. $J$. Immunol. 159:3009-3015.

11. Renz, H., H.R. Smith, J.E. Henson, B.S. Ray, C.G. Irvin, and E.W. Gelfand. 1992. Aerosolized antigen exposure without adjuvant causes increased $\mathrm{IgE}$ production and increased airway responsiveness in the mouse. J. Allergy Clin. Immunol. 89:1127-1138.

12. Holt, P.G., and C. McMenamin. 1989. Defence against allergic sensitization in the healthy lung: the role of inhalation tolerance. Clin. Exp. Allergy. 19: $255-262$.

13. Herscowitz, H.B. 1985. In defense of the lung: paradoxical role of the pulmonary alveolar macrophage. Ann. Allergy. 55:634-650.

14. Bilyk, N., and P.G. Holt. 1993. Inhibition of immunosuppressive activity of resident pulmonary alveolar macrophages by granulocyte/macrophage colony-stimulating factor. J. Exp. Med. 177:1773-1777.

15. Metcalf, D. 1986. The molecular biology and functions of the granulocyte-macrophage colony-stimulating factors. Blood. 67:257-267.

16. Morrissey, P.J., L. Bressler, L.S. Park, A. Alpert, and S. Gillis. 1987. Granulocyte-macrophage colony-stimulating factor augments the primary antibody response by enhancing the function of antigen-presenting cells. J. Immunol. 139:1113-1119.

17. Fischer, H.-G., S. Frosch, K. Reske, and A.B. Reske-Kunz. 1988. Granulocyte-macrophage colony-stimulating factor activates macrophages derived from bone marrow cultures to synthesis of MHC class II molecules and to augment antigen presentation function. J. Immunol. 141:3882-3888.

18. Sallusto, F., and A. Lanzavecchia. 1994. Efficient presentation of soluble antigen by cultured human dendritic cells is maintained by granulocyte/ macrophage colony-stimulating factor plus interleukin 4 and downregulated by tumor necrosis factor. J. Exp. Med. 179:1109-1118.

19. Chang, C.-H., M. Furue, and K. Tamaki. 1995. B7-1 expression of Langerhans cells is up-regulated by proinflammatory cytokines, and is downregulated by interferon- $\gamma$ or by interleukin-10. Eur. J. Immunol. 25:394-398.

20. Tao, M.-H., and R. Levy. 1993. Idiotype/granulocyte-macrophage colony-stimulating factor fusion protein as a vaccine for B-cell lymphoma. Nature. 362:755-758.

21. Dranoff, G., E. Jaffee, A. Lazenby, P. Golumbek, H. Levitsky, K. Brose, V. Jackson, H. Hamada, D. Pardoll, and R.C. Mulligan. 1993. Vaccination with irradiated tumor cells engineered to secrete murine granulocyte-macrophage colony-stimulating factor stimulates potent, specific, and long-lasting anti-tumor immunity. Proc. Natl. Acad. Sci. USA. 90:3539-3543.
22. Disis, M.L., H. Bernhard, F.M. Shiota, S.L. Hand, J.R. Gralow, E.S. Huseby, S. Gillis, and M.A. Cheever. 1996. Granulocyte-macrophage colonystimulating factor: an effective adjuvant for protein and peptide-based vaccines. Blood. 88:202-210.

23. Ellem, K.A., M.G. O'Rourke, G.R. Johnson, G. Parry, I.S. Misko, C.W. Schmidt, P.G. Parsons, S.R. Burrows, S. Cross, A. Fell, et al. 1997. A case report: immune responses and clinical course of the first human use of granulocyte-macrophage-colony-stimulating-factor-transduced autologous melanoma cells for immunotherapy. Cancer Immunol. Immunother. 44:10-20.

24. Simons, J.W., E.M. Jaffee, C.E. Weber, H.I. Levitsky, W.G. Nelson, M.A. Carducci, A.J. Lazenby, L.K. Cohen, C.C. Finn, S.M. Clift, et al. 1997. Bioactivity of autologous irradiated renal cell carcinoma vaccines generated by ex vivo granulocyte-macrophage colony-stimulating factor gene transfer. Cancer Res. 57:1537-1546.

25. Seelentag, W.K., J.-J. Mermod, R. Montesano, and P. Vassalli. 1987. Additive effects of interleukin 1 and tumor necrosis factor- $\alpha$ on the accumulation of the three granulocyte and macrophage colony-stimulating factor mRNA in human endothelial cells. EMBO (Eur. Mol. Biol. Organ.) J. 6:2261-2265.

26. Xing, Z., M. Jordana, T. Braciak, T. Ohtoshi, and J. Gauldie. 1993. Lipopolysaccharide induces expression of granulocyte/macrophage colony-stimulating factor, interleukin-8, and interleukin-6 in human nasal, but not lung, fibroblasts: evidence for heterogeneity within the respiratory tract. Am. J. Respir. Cell Mol. Biol. 9:255-263.

27. Kopf, M., F. Brombacher, P.D. Hodgkin, A.J. Ramsay, E.A. Milbourne, W.J. Dai, K.S. Ovington, C.A. Behm, G. Kohler, I.G. Young, and K.I. Matthaei. 1996. IL-5-deficient mice have a developmental defect in CD5 ${ }^{+}$B-1 cells and lack eosinophilia but have normal antibody and cytotoxic $\mathrm{T}$ cell responses. Immunity. 4:15-24.

28. Grusby, M.J., R.S. Johnson, V.E. Papaioannou, and L.H. Glimcher. 1991. Depletion of $\mathrm{CD}^{+}{ }^{+} \mathrm{T}$ cells in major histocompatibility complex class IIdeficient mice. Science. 253:1417-1420.

29. Xing, Z., Y. Ohkawara, M. Jordana, F.L. Graham, and J. Gauldie. 1996. Transfer of granulocyte-macrophage colony-stimulating factor gene to rat lung induces eosinophilia, monocytosis, and fibrotic reactions. J. Clin. Invest. 97: 1102-1110.

30. Bett, A.J., W. Haddara, L. Prevec, and F.L. Graham. 1994. An efficient and flexible system for construction of adenovirus vectors with insertions or deletions in early regions 1 and 3. Proc. Natl. Acad. Sci. USA. 91:8802-8806.

31. Ohkawara, Y., X.-F. Lei, M.R. Stämpfli, J.S. Marshall, Z. Xing, and M. Jordana. 1997. Cytokine and eosinophil responses in the lung, peripheral blood, and bone marrow compartments in a murine model of allergen-induced airways inflammation. Am. J. Respir. Cell Mol. Biol. 16:510-520.

32. Lei, X.-F., Y. Ohkawara, M.R. Stämpfli, J. Gauldie, K. Croitoru, M. Jordana, and Z. Xing. 1998. Compartmentalized transgene expression of granulocyte-macrophage colony stimulating factor (GM-CSF) in mouse lung enhances allergic airways inflammation. Clin. Exp. Immunol. 113:157-165.

33. Kung, T.T., D.M. Stelts, J.A. Zurcher, G.K. Adams III, R.W. Egan, W. Kreutner, A.S. Watnick, H. Jones, and R.W. Chapman. 1995. Involvement of IL-5 in a murine model of allergic pulmonary inflammation: prophylactic and therapeutic effect of an anti-IL-5 antibody. Am. Respir. Cell Mol. Biol. 13:360-365.

34. Vremec, D., and K. Shortman. 1997. Dendritic cell subtypes in mouse lymphoid organs. J. Immunol. 159:565-573.

35. Matsushima, G.K., and S.A. Stohlman. 1991. Distinct subsets of accessory cells activate Thy- $1^{+}$triple negative $\left(\mathrm{CD}^{-}, \mathrm{CD}^{-}, \mathrm{CD}^{-}\right)$cells and Th-1 delayed-type hypersensitivity effector T cells. J. Immunol. 146:3322-3331.

36. Ziegler, S.F., F. Ramsdell, and M.R. Alderson. 1994. The activation antigen CD69. Stem Cell. 12:456-465.

37. Kung, T.T., H. Jones, G.K. Adams, III, S.P. Umland, W.R. Kreutner, W. Egan, R.W. Chapman, and A.S. Watnick. 1994. Characterization of a murine model of allergic pulmonary inflammation. Int. Arch. Allergy Immunol. 105:83-90.

38. Manfreda, J., A.B. Becker, P.-Z. Wang, L.L. Roos, and N.R. Anthonisen. 1993. Trends in physician-diagnosed asthma prevalence in Manitoba between 1980 and 1990. Chest. 103:151-157.

39. Farber, H.J., W. Wattigney, and G. Berenson. 1997. Trends in asthma prevalence: the Bogalusa heart study. Ann. Allergy Asthma Immunol. 78:265-269.

40. Lang, R.A., D. Metcalf, R.A. Cuthbertson, I. Lyons, E. Stanley, A. Kelso, G. Kannourakis, D.J. Williamson, G.K. Klintworth, T.J. Gonda, and A.R. Dunn. 1987. Transgenic mice expressing a hemopoietic growth factor gene (GM-CSF) develop accumulation of macrophages, blindness, and a fatal syndrome of tissue damage. Cell. 51:675-686.

41. Pape, K.A., A. Khoruts, A. Mondino, and M.K. Jenkins. 1997. Inflammatory cytokines enhance the in vivo clonal expansion and differentiation of antigen-activated CD4 ${ }^{+}$T cells. J. Immunol. 159:591-598.

42. Churchill, L., B. Friedman, R.P. Schleimer, and D. Proud. 1992. Production of granulocyte-macrophage colony-stimulating factor by cultured human tracheal epithelial cells. Immunology. 75:189-195.

43. Ohtoshi, T., T. Tsuda, C. Vanchieri, J.S. Abrams, J. Gauldie, J. Dolovich, J.A. Denburg, and M. Jordana. 1991. Human upper airway epithelial cellderived granulocyte-macrophage colony-stimulating factor induces histaminecontaining cell differentiation of human progenitor cells. Int. Arch. Allergy Appl. Immunol. 95:376-384.

44. Vanchieri, C., J. Gauldie, J. Bienenstock, G. Cox, R. Scicchitano, A. 
Stanisz, and M. Jordana. 1989. Human lung fibroblast-derived granulocytemacrophage colony stimulating factor (GM-CSF) mediates eosinophil survival in vitro. Am. J. Respir. Cell. Mol. Biol. 1:289-295.

45. Thorens, B., J.-J. Mermod, and P. Vasalli. 1987. Phagocytosis and inflammatory stimuli induce GM-CSF mRNA in macrophages through posttranscriptional regulation. Cell. 48:671-679.

46. Pattemore, P.K., S.L. Johnston, and P.G. Bardin. 1992. Viruses as precipitants of asthma symptoms. I. Epidemiology. Clin. Exp. Allergy. 22:325-336.

47. Cypcar, D., and W.W. Busse. 1993. Role of viral infections in asthma. Immunol. Allergy Clin. N. Am. 13:745-767.

48. Sakamoto, M., S. Ida, and T. Takishima. 1984. Effect of influenza virus infection on allergic sensitization to aerosolized ovalbumin in mice. J. Immunol.
132:2614-2617.

49. Holt, P.G., J. Vines, and N. Bilyk. 1988. Effect of influenza virus infection on allergic sensitization to inhaled antigen in mice. Int. Arch. Allergy Appl. Immun. 86:121-123.

50. Woolley, K.L., E. Adelroth, M.J. Woolley, R. Ellis, M. Jordana, and P.M. O’Byrne. 1994. Granulocyte-macrophage colony-stimulating factor, eosinophils and eosinophil cationic protein in subjects with and without mild, stable, atopic asthma. Eur. Respir. J. 7:1576-1584.

51. Ohno, I., R. Lea, S. Finotto, J. Marshall, J. Denburg, J. Dolovich, J. Gauldie, and M. Jordana. 1991. Granulocyte/macrophage colony-stimulating factor (GM-CSF) gene expression by eosinophils in nasal polyposis. Am. J. Respir. Cell Mol. Biol. 5:505-510. 